\title{
A new look over the anesthetic approach of arthrogryposis multiplex congenita
}

Bernardo Ribeiro, Margarida Candeias, Inmaculada Gordillo Centro Hospitalar de Lisboa Ocidental, Dept of Anaesthesiology, Lisbon, Portugal

\section{o Introduction}

Arthrogryposis multiplex congenita (AMC) is a rare clinical condition characterized by congenital, non-progressive, multiple and persistent joint contractures with generalized muscle wasting found generally at birth (1) which may be associated with multiple congenital anomalies (2).

\section{o Case report}

\section{o Pre-op}

- Male, 26 years old, ASA III, 50kg;

- Tympanomastoidectomy of left ear and septoplasty; 4 and $1 / 2$ hours;

- BMI 16,6; Severe contractures of extremities and muscle atrophy;

- Vital signs, laboratory values, chest Xray and electrocardiogram unremarcable;

- Mallampati class II; Mouth opening > $4 \mathrm{~cm}$; TMD > 6cm; Good neck mobility.

\section{o Pos-op}

\section{- Analgesia with Paracetamol and Metamizol;}

- Discharged after 2 days.

\section{o Intra-op}

- Total endovenous general anaesthesia;

- Remifentanil - $1 \mathrm{mcg} / \mathrm{kg} / \mathrm{min}$; Propofol TCl - 4 $\mathrm{mcg} / \mathrm{ml}$;

Induction - Rocuronium - 0,6 mg/kg;

- Cormack Lehane - 2; OTI 7.5 cuffed tube.

- ASA standart + TOF watch + BIS + facial nerve monitoring + urinary debit;

- Remifentanil-0,05-0,25 $\mathrm{mcg} / \mathrm{kg} / \mathrm{min}$;

- Propofol TCl - 4-6 mcg/ml - Titrated to BIS - 40-

Maintenance $\quad{ }^{\circ}$

- EtCO2 - 29-33 mmHg; Core T - 35-37으.

- Nausea and vomiting prophylaxis;

- Removal of pharyngeal tamponade;

- Sugamadex ${ }^{\circledR}-2 \mathrm{mg} / \mathrm{kg}$; Perfusions stopped;

Recovery - Uneventfull extubation after reversal of the blockade.

\section{o Discussion}

AMC patients need meticulous care during surgeries since various associated anomalies can pose challenges to anaesthesiologists (2):

- Difficult airway, Malignant Hyperthermia $(\mathrm{MH})$, Myopathy, Difficult IV access, Difficult positioning (1)(2);

In this case we did not anticipate a difficult airway, but we had to use a muscle relaxant and intubate the patient. $\mathrm{MH}$ triggering agents were avoided and full recovery of neuromuscular blockade was achieved with Sugammadex ${ }^{\circledR}$ before extubation.

\section{o Summary}

Neuromuscular blockade and reversal with Rocuronium $(0,6 \mathrm{mg} / \mathrm{kg})$ and Sugammadex ${ }^{\circledR}$ (2 $\mathrm{mg} / \mathrm{kg}$ ), respectively, has proven to be a safe and effective approach and should be considered in patients with $\mathrm{AMC}$ if a general anaesthesia is required.

\section{References:}

$0 \quad$ 1. Jung JW, Heo BY, Oh EJ, Chung YH. Anesthesia in patients with arthrogryposis multiplex congenita: a report of 10 patients. Korean Journal of Anesthesiology. 2014;67(Suppl):S89-S90. doi:10.4097/kjae.2014.67.S.S89.

- 2. Pujari VS, Shivanna S, Anandaswamy TC, Manjunath AC. Arthrogryposis multiplex congenita: An anesthetic challenge. Anesthesia, Essays and Researches. 2012;6(1):78-80. doi:10.4103/0259-1162.103380. 